\title{
Application of Grey Clustering Analysis Method inMineral Prediction
}

\author{
Ma Yanying 1,2, \\ 1Jilin Engineering Normal University \\ 2Institute of Mineral Resources Prediction of Synthetic \\ Information,Jilin University \\ Changchun,China \\ e-mail: arnold0110@sina.com \\ * Corresponding Author \\ Li Xiuzhen \\ Jilin Engineering Normal University \\ Changchun,China
}

\author{
Wang Xue \\ Mathematics and Finice School \\ fuyang Teachers College, \\ Fuyang, China \\ Zhang $\mathrm{Na}$ \\ College of Art and Design \\ Shenyang Jianzhu University \\ Shen Yang, China
}

\begin{abstract}
In this paper, we establish grey clustering analysis model to predict mineral resources and apply it in the prediction of gold and copper minerals in the eastern Yanbian, Jilin province, by transforming the mineral prediction problem into grey clustering analysis problem.Among the geological units, 31 are selected as cluster objects, referencing to 3 evaluation indexes. And the prospecting target is divided into class $\mathrm{A}, \mathrm{B}$ and $\mathrm{C}$ with the comprehensive value of superiority degree calculated,and finally 21 gold copper mine areas are delineated,where 12 are class $A, 10$ and 9 of class $B$ and $C$ respectively. tested by the survey results, the prediction is more objective and effective having been which provide a reasonable scientific basis for strategic deployment in the research area of ore prospecting.
\end{abstract}

Keywords-grey system;clustering Yanbian;mineral resources prediction;

analysis;Eastern

\section{INTRODUCTION}

This article transform the mineral resources prediction problem into a grey clustering analysis, the predicting targets (samples or prospecting targets unit) are considered clustering objects, the object-related factors are considered clustering index prediction, the prediction of the desired levels (class A, B and C predicted target) are considered clustering grey class, the actual value of the relevant factors affected the predicting objects are considered whitening number and determine the whitening weight function and clustering weight function of grey class, then calculate the clustering coefficient, constitute clustering row vectors, cluster the objects according to the size of the components of row vectors, which could overcome the cluster analysis method in mathematical statistics based only on a random data lacking objective practice so as to achieve the purpose of prediction. Set grey clustering index is $i, i=1,2, \cdots, m$; grey number is $j, j=1,2 \cdots, p$;Object is $k, k=1,2 \cdots, n$ and the whitening value of the kth clustering object is $d_{k i}$ under the $\quad$ Ith $\quad$ clustering $\quad$ index, where
$k \in(1,2 \cdots, n), i \in(1,2, \cdots, m)$

From which, the whitening weight function can be $f_{i 1}(d)=\left\{\begin{array}{c}d / d_{h}(i), d \in\left[0, d_{h}(i)\right] \\ 1, d \in\left[d_{h}(i), \infty\right] \\ 0, d \notin[0, \infty]\end{array}\right.$

$$
\begin{gathered}
f_{i j}(d)=\left\{\begin{array}{c}
\frac{d-d_{j 1}(i)}{d_{j}(i)-d_{j 1}(i)}, d \in\left[d_{j 1}(i), d_{j}(i)\right] \\
\frac{d-d_{j 2}(i)}{d_{j}(i)-d_{j 2}(i)}, d \in\left[d_{j}(i), d_{j 2}(i)\right] \\
0, d \notin\left[d_{j 1}(i), d_{j 2}(i)\right]
\end{array}\right. \\
f_{i p}(d)=\left\{\begin{array}{c}
\frac{d-d_{p 2}(i)}{d_{p}(i)-d_{p 2}(i)}, d \in\left[d_{p}(i), d_{p 2}(i)\right] \\
1, d \in\left[0, d_{p}(i)\right] \\
0, d \notin\left[0, d_{p 2}(i)\right]
\end{array}\right.
\end{gathered}
$$

The rights for $\eta_{i j}$, then

$$
\eta_{i j}=d_{j}(i) / \sum_{i=1}^{m} d_{j}(i), i=1,2, \cdots, m ; j=1,2, \cdots, p
$$

the weight of the kth clustering object which belongs to the jth grey class is 


$$
\sigma_{k j}=\sum_{i=1}^{m} f_{i j}\left(d_{k i}\right) \eta_{i j}
$$

Find the maximum weight from $\sigma_{k}$, and the class belong to which is the factor $x_{k}$ as well.

\section{APPLICATIONS OF THE MODEL}

Eastern Yanbian in Jilin province is located in a complex geological environment with good metallogenic conditions, the dominant minerals are $\mathrm{Au}, \mathrm{Cu}$ and so on, where is the concentrated area of gold and copper mineralization and is the key area for gold and copper ore prospecting.

\section{A. Selection of grey clustering object}

Based on the geological characteristics of eastern Yanbian, the mineralization regularity and controlling conditions together with the guidence of the comprehensive information prospecting model, from the obtained geological information, we selected 31 statistical geological units (5 in which are known, 26 units are unknown) as the grey clustering objects.

\section{B. Selection of grey clustering index}

Choosing rational forecasting index is vital in mineral prediction,Feature analysis studies the relationship between the geological variables by the researching samples composed of known mineralization units, finds out the eological variables carried on the mineralization and the influence, then constructs the function between mineralization conditions and the geological variables in order to describe the metallogenic possibility quantitatively of the geological unit. Generalizing the function relation to unknown units will turn estimating metallogenic possibility of unknown units quantitatively into reality.

Grey relational analysis, measures the relative relation according to the geometric similarity of the sequence of broken lines, and is the quantitative and comparative analysis the dynamic process development trend on each factor in the system.

Delphy method is to deal with resources evaluation based on plenty of knowledge and prospecting working experience, a detailed understanding of the study area, geological and mineral resource assessment work with correct knowledge and attitude of the senior expert's experience and knowledge instead of geological variables, which can give full play to human factors and take advantage of more information.

The connection degree obtained by screening the determined characteristic analysis, the correlation coefficient obtained from grey connection analysis and the Delphy method score for the three grey clustering indexes, see table 1 .
TABLE I TABLE OF ORIGINAL DATA

\begin{tabular}{|c|c|c|c|}
\hline $\begin{array}{l}\text { element } \\
\text { number }\end{array}$ & $\begin{array}{c}\text { clustering } \\
\text { index } 1\end{array}$ & $\begin{array}{c}\text { clustering } \\
\text { index } 2\end{array}$ & $\begin{array}{c}\text { clustering } \\
\text { index } 3\end{array}$ \\
\hline 1 & 0.23 & 0.43 & 0.375 \\
\hline 2 & 0.6 & 0.82 & 0.625 \\
\hline 3 & 0.2 & 0.41 & 0.375 \\
\hline 4 & 0.58 & 0.88 & 0.55 \\
\hline 5 & 0.22 & 0.42 & 0.5 \\
\hline 6 & 0.17 & 0.39 & 0.375 \\
\hline 7 & 0.39 & 0.62 & 0.5 \\
\hline 8 & 0.5394 & 0.91 & 0.675 \\
\hline 9 & 0.17 & 0.39 & 0.3 \\
\hline 10 & 0.8096 & 0.89 & 0.75 \\
\hline 11 & 0.5 & 0.88 & 0.525 \\
\hline 12 & 0.57 & 0.92 & 0.65 \\
\hline 13 & 0.49 & 0.85 & 0.65 \\
\hline 14 & 0.44 & 0.72 & 0.45 \\
\hline 15 & 0.21 & 0.42 & 0.5 \\
\hline 16 & 0.52 & 0.96 & 0.45 \\
\hline 17 & 0.6795 & 0.97 & 0.8 \\
\hline 18 & 0.41 & 0.66 & 0.5 \\
\hline 19 & 0.3 & 0.50 & 0.5 \\
\hline 20 & 0.645 & 0.91 & 0.8 \\
\hline 21 & 0.53 & 1.00 & 0.7 \\
\hline 22 & 0.17 & 0.39 & 0.375 \\
\hline 23 & 0.35 & 0.56 & 0.575 \\
\hline 24 & 0.59 & 0.85 & 0.575 \\
\hline 25 & 0.1 & 0.35 & 0.3 \\
\hline 26 & 0.15 & 0.38 & 0.375 \\
\hline 27 & 0.3 & 0.50 & 0.375 \\
\hline 28 & 0.49 & 0.85 & 0.7 \\
\hline 29 & 0.52 & 0.96 & 0.575 \\
\hline 30 & 0.33 & 0.53 & 0.5 \\
\hline 31 & 0.5799 & 0.92 & 0.8 \\
\hline
\end{tabular}

Based on the working principle of the above mentioned model, the grey clustering weights and clustering coefficients of each index are obtained.

According to the closeness principle, we find the maximum weight from $\sigma_{k}$, the class which it belongs to is the target area as well. As $\sigma_{12}=0.8750$ is the maximum of $\sigma_{1}$, the first unit belongs to the second class, namely the class B target area.

According to the above steps and methods, we could find the other unit category successively, so as to judge the target level of each unit, see table 3. 
TABLE II COEFFICIENT VALUE OF GREY CLUSTER

\begin{tabular}{|c|c|c|c|c|}
\hline $\begin{array}{c}\text { Clusterin } \\
\text { g object }\end{array}$ & $\begin{array}{c}\text { Grey class } \\
\text { A }\end{array}$ & $\begin{array}{c}\text { Grey class } \\
\text { B }\end{array}$ & $\begin{array}{c}\text { Grey class } \\
\text { C }\end{array}$ & Category \\
\hline 1 & 0.3980 & 0.8750 & 0.8555 & B \\
\hline 2 & 0.7865 & 0.8639 & 0.1945 & B \\
\hline 3 & 0.3788 & 0.5472 & 0.8777 & $\mathrm{C}$ \\
\hline 4 & 0.7730 & 0.8278 & 0.2778 & $\mathrm{~B}$ \\
\hline 5 & 0.4384 & 0.6333 & 0.7555 & $\mathrm{C}$ \\
\hline 6 & 0.3596 & 0.5194 & 0.9221 & C \\
\hline 7 & 0.5808 & 0.8389 & 0.5333 & B \\
\hline 8 & 0.8170 & 0.8198 & 0.1389 & B \\
\hline 9 & 0.3307 & 0.4778 & 0.9221 & $\mathrm{C}$ \\
\hline 10 & 0.9383 & 0.6391 & 0.0556 & $\mathrm{~A}$ \\
\hline 11 & 0.7326 & 0.8583 & 0.3055 & B \\
\hline 12 & 0.8230 & 0.8111 & 0.1667 & $\mathrm{~A}$ \\
\hline 13 & 0.7653 & 0.8833 & 0.1667 & B \\
\hline 14 & 0.6192 & 0.8722 & 0.4777 & B \\
\hline 15 & 0.4346 & 0.6278 & 0.7555 & $\mathrm{C}$ \\
\hline 16 & 0.7422 & 0.7611 & 0.3889 & $\mathrm{~A}$ \\
\hline 17 & 0.9420 & 0.6392 & 0.0023 & A \\
\hline 18 & 0.6038 & 0.8722 & 0.4889 & B \\
\hline 19 & 0.4999 & 0.7222 & 0.6666 & B \\
\hline 20 & 0.9057 & 0.6917 & 0.0003 & $\mathrm{~A}$ \\
\hline 21 & 0.8576 & 0.7611 & 0.1111 & $\mathrm{~A}$ \\
\hline 22 & 0.3596 & 0.5194 & 0.9221 & $\mathrm{C}$ \\
\hline 23 & 0.5711 & 0.8250 & 0.5167 & B \\
\hline 24 & 0.7749 & 0.8528 & 0.2499 & B \\
\hline 25 & 0.2884 & 0.4167 & 0.9999 & $\mathrm{C}$ \\
\hline 26 & 0.3480 & 0.5028 & 0.9444 & $\mathrm{C}$ \\
\hline 27 & 0.4519 & 0.6528 & 0.7777 & $\mathrm{C}$ \\
\hline 28 & 0.7845 & 0.8556 & 0.1111 & $\mathrm{~B}$ \\
\hline 29 & 0.7903 & 0.8306 & 0.2499 & $\mathrm{~B}$ \\
\hline 30 & 0.5230 & 0.7556 & 0.6333 & B \\
\hline 31 & 0.8845 & 0.7223 & 0.0035 & $\mathrm{~A}$ \\
\hline
\end{tabular}

\section{ANALYSIS ON THE FORECASTING RESULTS}

From the results in table 2, we can see that the best comprehensive effects of units are 10,12,16, 17, 20, 21and 31, which belong to class A target area and could be the preferred targets for gold copper mineral prospecting arrangement; the comprehensive effects of units $1,2,4,7,8,11,13,14,18,19,23,24,28,29$ and 30 come the second ,belonging to class B target area, which has certain potential prospect; and the rest $3,5,6,9,15$, $22,25,26$ and 27 belong to class $C$ target area with the worst comprehensive effects, mineralization future needs further work. Since 8, 10, 17, 20 and 31are known units when calculated by grey clustering analysis, all of the units are class A target area besides number 8 unit class B, which illustrates the eastern region of Yanbian geological prospecting , and investigation results are basically consistent with [10] grey clustering analysis, therefore, the method is feasible.

\section{PROPOSALS ON RECENT EXPLORATION WORK}

The No. 10, 17, 20, and No. 31 ore prospecting target areas are known ore bearing units which could output gold and silver mineral. In order to discover new ore deposits and ore prospecting target areas and provide favorable reference experience of evaluation target areas, the outskirt of the peripheral area, the deep prospecting and verification work could be arranged. Where the No.10 target zone produced Ciweigou gold-silver deposit, the abnormal geochemical chemistry is composed of $\mathrm{Au}, \mathrm{Ag}$, $\mathrm{Bi}$ and As elements.

The No.12, 16 and No.21are the areas where the most part of the prospecting work is arrarged, mainly focusing in Ma Dida, Liushuhezi and Taoyuan Dong zone, whose prospecting future is obvious. We may find goldcopper mineral resources and provide valuable information for further work.

The No. 31 and No. 17 verification work is arranged in the north in order to find out the meanings of No.5 and 6 target areas for further work. The outskirt of the peripheral area and the deep prospecting work are arranged in the south of the prospect area. In order to discover new resources and enlarge the available amount of resources, comprehensive studying, field measurement and verification work were carried out.

\section{CONCLUSIONS}

Applying grey clustering analysis method to Eastern Yanbian to evaluate prospecting work can quantitatively classify the metallogenic areas, which shows the advantages of solving the incomplete information system and overcomes the deficiency in clustering analysis method of mathematical statistics in solving practical problems only by randomly sampling digital classification which neglects the objective reality. The method can not only deal with the completely known index relation with the main factors, but also handle those uncertain index relations with main factors, and it can draw the more accurate and reliable classification, which will provide references and suggestions for the next working deployment.

\section{REFERENCES}

[1] LI Lin, SANG Shuxun,HUANG Huazhou, et al. Application of Grey Clustering Analysis in Evaluation of Effective Supply Capacity of Coal Resources.Coal Geology \& Exploration,vol.37,pp.12-16,2009.

[2] The prediction report on mineral resources of gold, copper and Tungsten of East Yabian area.Item number 20080457, 2008-2010.

[3] XIE Gui-m ing.The regional metal logenetic model of gold deposits in East Hunchun District of Jilin Province. Gold Science and Technology,vol.8,pp.16-27,2000.

[4] MAO Xin-hu, LIU Zhan-kui, LI Xiu-qing. Applying the method of grey cluster relation analysis to evaluate the geological disaster fatalness of mine subarea. Journal of Southwest University for Nationalities(Natural Science Edition),vol.34,pp.545-551, 2008.

[5] ZHANG Hai-yan,WANG Xin-min,YIN Hui,et al. Threshold Regressive Modle and Cluster Analysis of Sediment-Related Disaste. Journal of Jilin University:Journal of Jilin University: Earth Science Edition,vol.41,pp.529-535,2011.

[6] DONG Feng-juan,SUN Wei, HU Xu-jun, et al. Application of Grey Analytic Hierarchy Process to Divide Flow Units_- A Case from Sanjianfang Formation of Qiuling Oilfield. Journal of Jilin University:Journal of Jilin University: Earth Science Edition. vol.41,pp.529-535, 2010.

[7] Jiang Ying and Zhang QiuWen .Research on the Grey Assessment System of Dam Failure Risk. Journal of Computers, Vol. 7, pp. 2334-2341, 2012

[8] Sifeng Liu, Jeffrey Yi Lin Forrest.Grey Systems: Theory and Applications. Springer ress.2010.

[9] Sun xun, Zhang Yinjie, Sun Linde. The soft measurement of quantitative of gastric juice ased on grey mathematics. Practice and Recognition of Mathematic. Vol.42, pp.63-69, 2012.

[10] Yin Hongjun, Zhang Junting, Zhang Huanhuan. He Huaidong. Applying the Grey Relation Analysis to Ascertain the Formula of 
Level Injected Water. Practice and Recognition of Mathematic. Vol.42, pp.94-99, 2012.

[11] Hongli Wang.Extension of Grey Random Model based on Cloud
Model and Its Application in Software Evaluation of Users. Journal of Computers, Vol. 8, pp. 2322-2329, 2013 